\title{
Markers of lower respiratory tract infections in emergency departments
}

\author{
Dursun Tatar ${ }^{1}$, Gunes Senol ${ }^{2}$, Ceyda Anar ${ }^{1}$ and Gultekin Tibet ${ }^{1}$
}

\begin{abstract}
Background: Acute respiratory tract infections are the common causes for admission to emergency department. Appropriate diagnosis and initiating treatment on time are important for reducing morbidity and mortality rate due to lower respiratory tract infection (LRTI). The aim of this study is to determine if C-reactive protein (CRP) levels and white blood cells (WBC) count are considerable markers to help rapid diagnosis and prediction of antibiotic need for lower respiratory infections in emergency departments. The relationships between infectious agents and those markers have also been evaluated.
\end{abstract}

Methods: Study subjects and control group were selected by defined criteria. Patients were analyzed and assessed for CRP and WBC, sputum Gram stain and culture besides routine laboratory tests and chest X-Rays.

Results: One hundred and ninety four episodes out of 175 patients were evaluated for the study. CRP level and WBC count were detected significantly higher in patients ofstudy group than in those of control group.

Pseudomonas aeruginosa and Haemophilus influenzae were the pathogens most often isolated.

Conclusion: In conclusion, CRP and WBC sputum are important markers for diagnosis of LRTI at the emergency departments and results of microbiological analysis of respiratory specimens were correlated with these markers.

Trial registration: Registation number of ethic committee of Dr. Suat Seren Chest Diseases and Surgery Training and Research Hospital: 28.04.2006/114

Keywords: C-reactive protein, Gram stain, Lower respiratory tract infections, Sputum culture, White blood cells

\section{Background}

Respiratory tract infections are among the most common reasons for admission to emergency departments (ED) [1]. Although antibiotic treatment is considered necessary only for community-acquired pneumonia and small subgroups of the other lower and upper respiratory tract infections, antibiotics are prescribed to about $80 \%$ of patients consulting for lower respiratory tract infection (LRTI) [2]. Signs and symptoms are of limited value in identifying those patients who need antibiotic treatment [1]. Diagnostic uncertainty and patient-related factors, such as patient expectations and pressure, often lead to unjustified antibiotic prescriptions by emergency physicians [3].

LRTI mainly include bronchitis, bronchiolitis and pneumonia [4]. Acute exacerbations of chronic obstructive

\footnotetext{
* Correspondence: drshenol@yahoo.com

${ }^{2}$ Department of Infectious Diseases and Clinical Microbiology, Dr. Suat Seren

Chest Diseases and Surgery Training and Research Hospital, Yenisehir, Izmir, Turkey Full list of author information is available at the end of the article
}

pulmonary disease (AE-COPD) and pneumonia often cause LRTIs in ED visits [5]. Emergency departments are required to diagnose and manage patients with severe pneumonia associated with a high morbidity and mortality and antibiotic timing is accepted as a measure of hospital quality $[6,7]$.

COPD was detected in $23 \%$ of respiratory diseases and caused mortality in $3.3 \%$ of all hospitalizations in Turkey [8]. In developed countries, it is the fourth leading cause of death with $4.3 \%$; but it is the second with $10.8 \%$ rate in developing countries [9].

The Gram stain method is one of the most commonly used technique for the rapid diagnosis of bacterial infections. The result of the Gram stain can be reported in less than 10 minutes, giving the physician a reasonable idea of its identity upon which to base treatment. Gram staining provides a presumptive diagnosis and some indication of the organism involved without waiting for culture results. The specimen is obtained by deep cough and should be grossly purulent. Culture should be

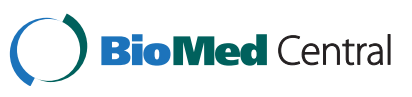




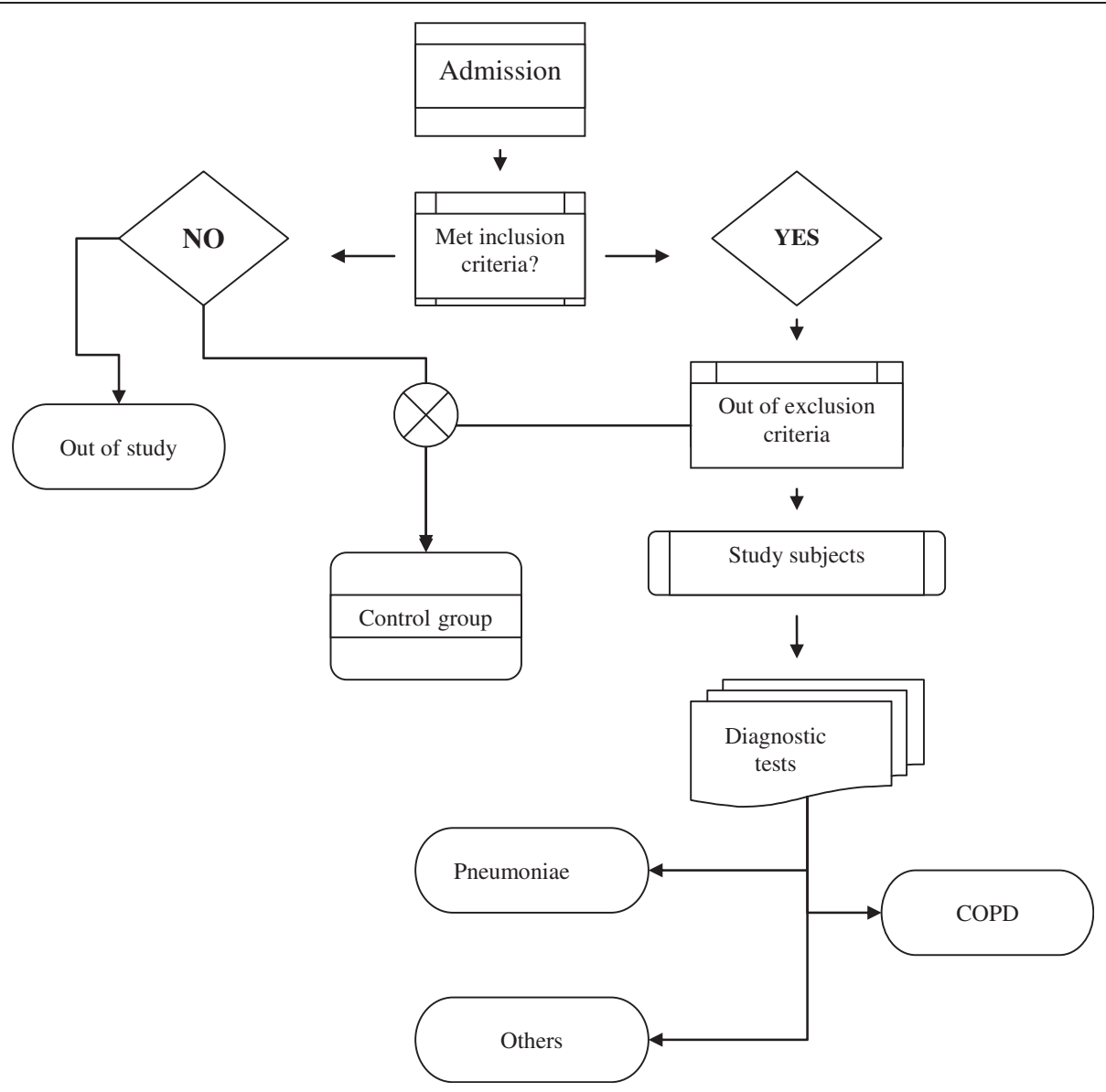

Figure 1 Flowchart of the selection method of study and control groups.

performed only if the specimen meets strict cytological criteria (except for detection of legionella or mycobacteria). Controversy surrounds the role of Gram stain and culture analysis of expectorated sputum in patients with community-acquired pneumonia. Most reports suggest that these tests have poor positive and negative predictive value in LRTI patients [10]. However, these tests should be performed to try to identify etiologic organisms in the hope of reducing microbial resistance to drugs, unnecessary drug costs, and avoidable side effects of empirical antibiotic therapy [11].

In Turkey, according to national statistics, $14.8 \%$ of all hospitalizations are due to respiratory disease other than tuberculosis. Lower respiratory infections except tuberculosis are the cause of the whole mortality in $4.1 \%$ percentage. Respiratory diseases and respiratory infections are reported $13.8 \%$ and $3.3 \%$ rate, respectively [12].

The aim of this study is to determine etiological bacterial agents and the possible inflammatory markers in patients with or without adequate respiratory secretions who presented to the ED of one hospital with symptoms of respiratory infection.

\section{Methods}

The study was planned as a prospective, open observational study in ED of a tertiary referral center for chest diseases and chest surgery.

Patients who met the inclusion criteria in 2006 were enrolled in the study.

Inclusion criteria:

1. Acute illness present for 14 days or less;

2. At least one lower respiratory tract symptom (cough, sputum production, dyspnea, wheezing, chest pain);

Table 1 Demographic data of the patients and controls

\begin{tabular}{lccccc}
\hline & $\mathbf{n}$ & Gender & Age & \multicolumn{2}{c}{ Smoking } \\
\cline { 5 - 6 } & & & & $\%$ & Package/year \\
\hline AECOPD & 115 & $109 \mathrm{M}, 6 \mathrm{~F}$ & $64.4 \pm 11.4$ & $94 \%$ & $52.7 \pm 24.7$ \\
PNEUMONIA & 64 & $55 \mathrm{M}, 9 \mathrm{~F}$ & $64.3 \pm 12.4$ & $74 \%$ & $51.6 \pm 26.0$ \\
*OTHERS & 15 & $10 \mathrm{M}, 5 \mathrm{~F}$ & $68.3 \pm 9.6$ & $66 \%$ & $54.5 \pm 25.2$ \\
TOTAL CASES & 194 & $174 \mathrm{M}, 20 \mathrm{~F}$ & $64.2 \pm 11.7$ & $92 \%$ & $52.5 \pm 25.6$ \\
CONTROLS & 50 & $31 \mathrm{M}, 19 \mathrm{~F}$ & $46.2 \pm 17.4$ & $42 \%$ & $20.5 \pm 8.5$ \\
\hline
\end{tabular}

* Asthma $n=3$, interstitial pulmonary diseases $n=2$, acute bronchitis, tracheitis, silicosis, operated esophageal carcinoma.

$F$, Female, $M$, Male. 
Table 2 Symptoms of the patients

\begin{tabular}{clllllll}
\hline & N & \multicolumn{5}{c}{ SYMPTOMS } \\
\cline { 3 - 7 } & & \multicolumn{7}{c}{$\mathbf{n}(\%)$} \\
\cline { 3 - 7 } & & Dyspnea & Cough & Expectoration & Fever & Chest pain & Hemoptysis \\
\hline AECOPD & 115 & $115(100)$ & $65(56.5)$ & $52(45.2)$ & $1(0.9)$ & $1(0.9)$ & $2(1.7)$ \\
PNEUMONIA & 64 & $59(92.1)$ & $44(68.7)$ & $37(57.8)$ & $15(23.4)$ & $2(3.1)$ & $5(7.8)$ \\
OTHERS & 15 & $13(86.6)$ & $7(46.6)$ & $4(26.6)$ & $1(6.6)$ & 0 & $3(20)$ \\
\hline
\end{tabular}

3. No alternative explanation of cough for example, not sinusitis, pharyngitis, or a new presentation of asthma.

4. And/or fever.

\section{Exclusion criteria}

Confirmed tuberculosis cases were excluded from the study. Patients affected with cardiovascular diseases, thromboembolism, pregnancy, those who used corticosteroids within the last six months, and those who had been discharged from hospital within seven days before were not included.

Control cases were randomly selected from patients with respiratory complaints, retrospectively.

Diagnosis of COPD was confirmed by spirometry after acute exacerbation in patients at their first admission to the hospital. Pneumonia was diagnosed by infiltration on chest X-Ray in addition of inclusion criteria. Flow chart of the selection method is shown in Figure 1.

\section{Microbiology}

Bacteriological sputum cultures, WBC count and CRP test were performed for all cases besides other conventional tests according to the nature of cases on the day of admission. Sputum samples were sent to the bacteriology division. They were previously examined macroscopically for evaluating the qualification for culture by laboratory technician. Samples which included saliva or food within insufficient respiratory secretions were rejected. Sputum samples were analyzed by Gram stains and culture methods. Sputum purulence was identified as above 25 polymorphonuclear leucocytes (PNL) per low power microscopic field [11]. Identification of micro-organisms was done by conventional microbiological methods and semi-automated systems (Crystal, BD, Maryland, USA). Antibiotic susceptibility of bacteria was done by disc diffusion method according to CLSI recommendations. CRP and WBC were studied in serology division of microbiology laboratory. CRP levels were tested by nephelometric method. (Array 360 System, Beckman Coulter, USA). WBC was counted by Coulter hematology analyzer (Beckman Coulter, USA).

SPSS 15 program was used for statistical analysis. Distribution of data was evaluated by Kolmogorov Smirnov test. Analysis of parametric variables was performed with t test; Kruskal Wallis and Mann-Whitney tests were applied for nonparametric distributed variables. Chi-square test was used for analyzing categorical data. $p$ under 0.05 was accepted as significant.

This research was carried out in compliance with the Helsinki Declaration, and approved by ethic committee of Dr. Suat Seren Chest Diseases and Surgery Training and Research Hospital, İzmir, Turkey with 28.04.2006/ 114 registration number.

\section{Results}

In the study period, 31,257 episodes of 21,346 patients were examined and 2,298 cases of pneumonia and other lower respiratory infections were detected in 1,480 in patients in ED.

The cases which met the inclusion criteria (194 episodes of 175 patients) and 50 controls were studied. The pathological conditions of control patients were twenty one common cold, ten pharyngitis, eight asthma, four pneumothorax, two thoracic injury, two foreign body aspiration, one corpulmonare, one acute laryngitis and one sinusitis.

Table 1 shows demographic data of the cases and controls.

Prevalence of smoking and pack/year were found significantly higher in the LRTI group than in controls.

Symptoms and laboratory findings of the patients are reported in Tables 2 and 3, respectively. Shortness of breath was the major symptom in all patients in the LRTI group. Fever was seen in higher rate in pneumonia cases than in other cases. Comparative values of CRP and WBC in cases and controls are shown in Figure 2a and 2b. CRP and WBC values were significantly higher in LRTI subjects than in controls $(\mathrm{p}<0.001)$. Differential leukocyte count indicated normal or neutrophilic increase in patients.

In Figure 3, microbiological analysis of sputum samples are shown. WBC and CRP levels according to microscopic features of sputum are detailed in Table 4. The results showed that when pathogen isolation was not possible, CRP was an important marker for diagnosis

Table 3 Laboratory findings of study subjects and controls

\begin{tabular}{cccc}
\hline & N & CRP & WBC \\
\hline AECOPD & 115 & $9.8+9.9$ & $12640+4800$ \\
PNEUMONIA & 64 & $11.2+8.9$ & $14490+6400$ \\
OTHERS & 15 & $14.0+12.5$ & $13100+6200$ \\
CONTROLS & 50 & $3,5 \pm 1.9$ & $8100 \pm 3100$ \\
\hline
\end{tabular}



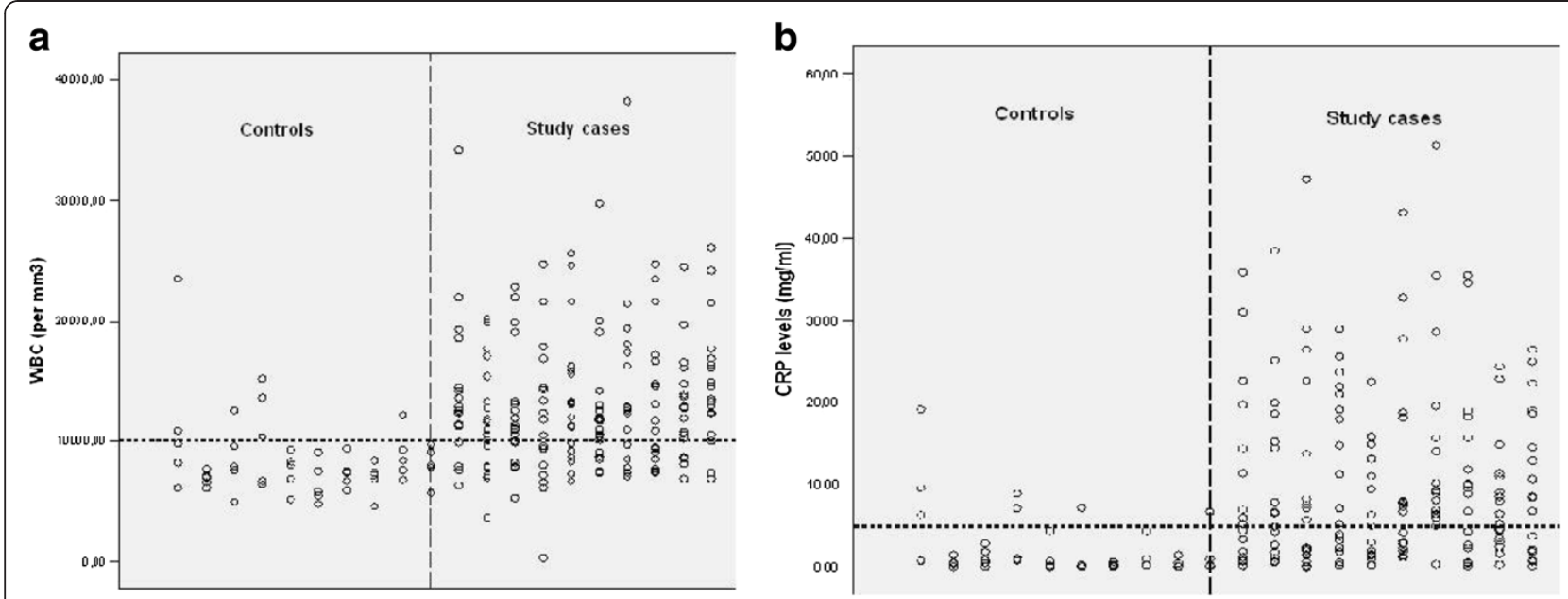

Figure 2 a. WBC values of study and control cases. $\mathbf{b}$. CRP values of study and control cases.

ofLRTI. Pseudomonas aeruginosa and Haemophilus influenzae were the most frequent pathogens.

Mean number of previous hospital admissions was significantly higher in $P$. aeruginosa infections $(\mathrm{p}=0.142)$. In infections due to other agents, the numbers of previous admissions did not show significant difference.

\section{Discussion}

We have reported in this study serum CRP responses, WBC count and sputum purulence in patients with lower respiratory infections according to data obtained from a population-based study that includes all spectra of the disease together with strict criteria for unequivocal diagnosis. The present results provide evidence for the usefulness of the CRP assay, WBC count and sputum microbiology in the diagnosis of LRTI in ED and to evaluate the need for antibiotic therapy.

CRP is an acute-phase protein with levels quickly rising during inflammatory processes [2]. Relationship between CRP and infection of the lower respiratory tract was indicated by different studies in literature. High CRP levels were reported sensitive and specific to determine lower respiratory diseases [13]. Almirres et al. reported that CRP levels have been shown to be also useful in confirming the diagnosis, since they were significantly higher in patients with true pneumonia than in those in whom the diagnosis was not confirmed at follow up [14]. Macfarlane et al. in a study of lower respiratory tract infections in patients attending an outpatient setting, reported that $65 \%$ of patients with radiographically confirmed disease showed high serum CRP levels (above $5 \mathrm{mg} / \mathrm{dL}$ ) compared with $40 \%$ in those with radiographic findings that were consistent with infection, and $11 \%$ in those who had no changes consistent with infection [1]. Melbye et al. showed that serum CRP level of above $5 \mathrm{mg} / \mathrm{dL}$ in patients with symptoms of respiratory infection who had been treated as outpatients had a sensitivity of $54 \%$ and a specificity of $95 \%$ for the diagnosis of pneumonia [15]. In a study by Castro-Guardiola et al. on cases of pneumonia diagnosed at the hospital ED, mean serum CRP levels of $18.1 \mathrm{mg} / \mathrm{dL}$ were found in cases of confirmed pneumonia and much lower titers in false-positive cases [16]. Gomperts et al. showed that purulent exacerbations were associated with significant bronchial and systemic inflammation and positive bacterial cultures. CRP values were reported significantly high in the purulent bronchitis [17]. A CRP test result adds incremental information to the physicians' information obtained from medical history and physical examination [18]. The introduction of CRP testing to assist antibiotic prescribing decisions in LRTI resulted in a reduction of antibiotic use [2].

High WBC count was found associated with AECOPD as well as with pneumonia in literature. Sin et al. pointed out that blood WBC were elevated in a directly

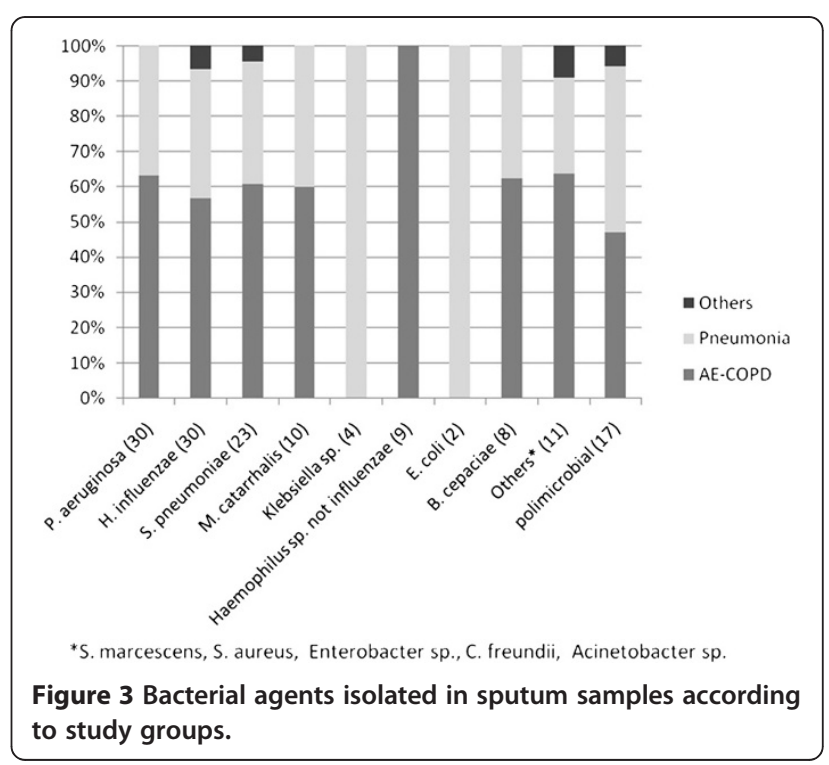


Table 4 WBC and CRP levels according to microscopic features of sputum

\begin{tabular}{|c|c|c|c|c|c|}
\hline & & $>5 \mathrm{mg} / \mathrm{dl}$ & $0.8-5 \mathrm{mg} / \mathrm{dl}$ & $<0.8 \mathrm{mg} / \mathrm{dl}$ & $\mathrm{WBC}>10000 / \mathrm{ml}$ \\
\hline & & \multicolumn{4}{|c|}{$n($ mean $\pm S D)$} \\
\hline \multirow[t]{3}{*}{ Microscopy* of sputum samples } & $>25 \mathrm{PNL}$ & $20(17,7 \pm 12,3)$ & $7(2,4 \pm 1,1)$ & $1(0,3 \pm 0)$ & $19(12275 \pm 5300)$ \\
\hline & $10-25$ PNL & $10(13,2 \pm 7,2)$ & $2(2,8 \pm 0,4)$ & 0 & $8(15680 \pm 8390)$ \\
\hline & $<10$ PNL & $14(18,8 \pm 16,7)$ & $5(2,9+0,9)$ & $8(0,3 \pm 0,2)$ & $19(13640+6000)$ \\
\hline No expectoration & & $2(29,2 \pm 16,4)$ & $6(2,9 \pm 1,2)$ & $3(0,5 \pm 0,4)$ & $5(9950 \pm 4440)$ \\
\hline
\end{tabular}

*per low power field $(\times 10)$.

proportional manner with severity of exacerbation [19]. Gan et al. also reported high WBC in AECOPD with has been showing with increased systemic inflammation that reflected the severity of exacerbation [20]. Roche et al. concluded that leukocyte count would be remarkable in patients hospitalized for COPD exacerbations with purulent sputum [21]. Besides, some studies disagreed that WBC elevates in COPD, because it was found a normal WBC count and markedly elevated CRP level in AECOPD [13,22]. Thus, it has been suggested that it is reasonable to check CRP level in addition to WBC count in patients admitted the ED due to fever.

Performing microbiological research as early as during ED admission could help a definitive diagnosis. Atasever et al. suggested that sputum samples, which were collected from patients at the moment they applied to ED, are important for isolation of etiologic agents of lower respiratory infections. They also reported that high CRP level and high WBC count were found significant in diagnosis of respiratory infections. They concluded that results would help when deciding if antibiotics should initially be used to treat patients with AECOPD [23].

On the other hand, van der Meer reported in his review that testing for CRP is not sufficiently sensitive and specific to rule out an infiltrate on chest radiograph and bacterial etiology of LRTIs. He concluded that the evidence was not sufficient to support a wide introduction of CRP as a rapid test to guide antibiotics prescription [24].

Additionally we found that isolation of $P$. aeruginosa was getting higher along with high number of previous admissions. Russel et al. reported that a quarter of potentially pathogenic microorganisms colonize the patients with COPD during their stable periods. Exacerbation is associated with the overgrowth of these microorganisms and with the appearance of $P$. aeruginosa in the lower airway, which is associated with exacerbation symptoms independent of load [25]. Ohmagari et al proposed that extended spectrum antibiotics may need to be used as first-line empirical therapy for COPD with prior infection that requires hospitalization, and as alternative, antipseudomonal antibiotic regimens may need to be considered [26].

Although it has not been tested in our study, procalcitonin (PCT) is an important biomarker worth to discuss in this issue. PCT was found very useful to assess the severity of respiratory disease and the necessity of antibiotic use as CRP in various studies, and it has been reported that PCT is a more sensitive marker than CRP. Cut off values of PCT were recommended between 0,15 $\mathrm{ng} / \mathrm{ml}$ and $0,5 \mathrm{ng} / \mathrm{ml}$ for the best sensitivity and specificity in different studies $[27,28]$.

A limitation of this study could be considered that data were not available about prior antibiotic consumption of patients that might have an effect on likelihood of respiratory flora and sputum culture. Other limitations of the study were the inability of identification of viral agents and the lack of studying PCT.

\section{Conclusion}

In conclusion we beleive that CRP and WBC are good diagnostic markers especially for patients who do not expectorate sputum sample. Microbiological investigation of sputum samples should be done in adequate cases in order establish a rational antibiotic treatment and avoid unnecessary drug resistance. History of hospital admission is important for selection of empiric antibiotics.

\section{Competing interests}

The authors affirm that they have no conflict of interest in relation to the subject of the study.

\section{Author details}

${ }^{1}$ Department of Respiratory Medicine, Dr. Suat Seren Chest Diseases and Surgery Training and Research Hospital, Izmir, Turkey. ${ }^{2}$ Department of Infectious Diseases and Clinical Microbiology, Dr. Suat Seren Chest Diseases and Surgery Training and Research Hospital, Yenisehir, Izmir, Turkey.

Received: 23 November 2012 Accepted: 17 January 2013

Published: 15 March 2013

\section{References}

1. Macfarlane J, Holmes W, Gard P, Macfarlane R, Rose D, Weston V, Leinonen M, Saikku P, Myint S: Prospective study of the incidence, etiology and outcome of adult lower respiratory tract illness in the community. Thorax 2001, 56:109-114.

2. Holmes WF, Macfarlane JT, Macfarlane RM, Hubbard R: Symptoms, signs, and prescribing for acute lower respiratory tract illness. Br J Gen Pract 2001, 51:177-181.

3. Coenen S, Michiels B, Renard D, Denekens J, Van Royen P: Antibiotic prescribing for acute cough: the effect of perceived patient demand. $\mathrm{Br} J$ Gen Pract 2006, 56:183-190.

4. Liu C: Infections of large and small airways. In Infectious diseases: a modern treatise of infectious process. 5th edition. Edited by Hoeprich PD, Jordan MC, Ronald AR. Philadelphia: J. P. Lippincott; 1994:341.

5. Mohan A, Premanand R, Narayana Reddy L, Mangu H, Sharma S, Kamity R, Bollineli S: Clinical presentation and predictors of outcome in patients 
with severe acute exacerbation of chronic obstructive pulmonary disease requiring admission to intensive care unit. BMC Pulm Med 2006, 19:27

6. Suzuki M, Sayama K, Chiyotani AK, Arai K, Ishizuka S, Tomioka H, Kobayashi $K$ : Risk stratification of adult pneumonia in a tertiary emergency center in Japan. Int Med 2003, 42:676-680

7. Pines JM, Morton MJ, Datner EM, Holander JE: Systematic delays in antibiotic administration in the emergency department for adult patients admitted with pneumonia. Acad Emerg Med 2006, 13:939-945.

8. Lopez A, Akgun S, Chalapati R, Aydın O, Karakan E: Results. In National disease load and cost - effectiveness project: final report. Edited by Ersoy K, Kisa A, Kavuncubası S. Ankara: Ministry of Health; 2004:306.

9. World Health Organization: The ten leading causes of death by broad income group. Fact sheet N³10 / February 2007

10. Morris CG, Safranek S: Is sputum evaluation useful for patients with community-acquired pneumonia? Fam Pract 2005, 54:279-280.

11. Bartlett JG: Diagnostic test for etiologic agents of community-acquired pneumonia. Infect Dis Clin North Am 2004, 18:809-827.

12. National statistics instutude. Health statistics: http://www.turkstat.gov.tr/ VeriBilgi.do?tb_id $=6$ \&ust id $=1$ (last accessed 01.03.2009).

13. Bircan A, Kaya O, Gokırmak M, Ozturk O, Sahin U, Akkaya A: C-reactive protein, leukocyte count and ESR in the assessment of severity of community-acquired pneumonia. Tuberd Toraks 2006, 54:22-29.

14. Almirall J, Bolivar I, Toran P, Pera G, Boquet X, Balanzo X, Sauca G, Community-Acquired Pneumonia Maresme Study Group: Contribution of C-reactive protein to the diagnosis and assessment of severity of community-acquired pneumonia. Chest 2004, 125:1335-1342.

15. Melbye H, Hvidsten D, Holm A, Nordbo SA, Brox J: The course of C-reactive protein response in untreated upper respiratory tract infection. $\mathrm{Br} J \mathrm{Gen}$ Pract 2004, 54:653-658.

16. Castro-Guardiola A, Armengou-Arxé A, Viejo-Rodríguez A, PeñarrojaMatutano G, Garcia-Bragado F: Differential diagnosis between communityacquired pneumonia and non-pneumonia diseases of the chest in the emergency ward. Eur J Intern Med 2000, 11:334-339.

17. Gomperts S, Brien C, Bayley DL, Hill SL, Stockley RA: Changes in bronchial inflammation during acute exacerbations of chronic bronchitis. Eur Respir J 2001, 17:1112-1119.

18. Sarioglu N, Alpaydin A, Coskun A, Celik P, Ozyurt B, Yorgancioglu A: Relationship between BODE index, quality of life and inflammatory cytokines in COPD patients. Multidiscip Resp Med 2010, 5:84-91.

19. Sin Don D, Man SF: Why are patients with chronic obstructive pulmonary disease at increased risk of cardiovascular diseases? Circulation 2000, 107:1511-1519.

20. Gan WQ, Man SF, Senthilselvan A, Sin Don D: Association between chronic obstructive pulmonary disease and systemic inflamation: A systematic review and a metaanalysis. Thorax 2004, 59:574-580

21. Roche N, Kouassi B, Rabbat A, Mounedji A, Lorut C, Huchon G: Yield of sputum microbiological examination in patients hospitalized for exacerbations of chronic obstructive pulmonary disease with purulent sputum. Respiration 2007, 74:19-22.

22. Kuan TL, Lin TJ, Chan HM: Characteristics of febrile patients with normal white blood cell counts and high C-reactive protein levels in an emergency department. Kaohsiung J Med Sci 2008, 24:248-253.

23. Atasever A, Goksel T, Aysan T, Cok G, Soyer S, Karakus H: Lower respiratory tract infections in patients with lung cancer. Toraks Dergisi 2006, 7:79-83.

24. van der Meer V, Neven AK, van den Broek PJ, Assendelft WJJ: Diagnostic value of $C$ reactive protein in infections of the lower respiratory tract: systematic review. BMJ 2005, 331:26.

25. Russell A, Monsó E, Soler N, Torres F, Angrill J, Riise G, Zalacain R, Morera J, Torres A: Microbiologic determinants of exacerbation in chronic obstructive pulmonary disease. Arch Intern Med 2005, 165:891-897.

26. Ohmagari N, Hanna H, Graviss L, Hackett B, Perego C, Gonzales V, Dvorak T, Hogan H, Hachem R, Rolston K, Raad I: Risk factors for infections with multidrug-resistant Pseudomonas aeruginosa in patients with cancer. Cancer 2005, 104:205-212.

27. Seligman R, Ramos-Lima LF, Oliveira Vdo A, Sanvicente C, Pacheco EF, Dalla Rosa K: Biomarkers in community-acquired pneumonia: a state-of-the-art review. Clinics 2012, 67:1321-1325.
28. España PP, Capelastegui A, Bilbao A, Diez R, Izquierdo F, de Lopez Goicoetxea MJ, Gamazo J, Medel F, Salgado J, Gorostiaga I, Quintana JM: Population study of pneumonia (PSoP) group: utility of two biomarkers for directing care among patients with non-severe community-acquired pneumonia. Eur J Clin Microbiol Infect Dis 2012, 31:3397-3405.

doi:10.1186/2049-6958-8-20

Cite this article as: Tatar et al:: Markers of lower respiratory tract infections in emergency departments. Multidisciplinary Respiratory Medicine 2013 8:20.

\section{Submit your next manuscript to BioMed Central and take full advantage of:}

- Convenient online submission

- Thorough peer review

- No space constraints or color figure charges

- Immediate publication on acceptance

- Inclusion in PubMed, CAS, Scopus and Google Scholar

- Research which is freely available for redistribution 